\title{
PRECONCEITO E EDUCAÇÃO INFANTIL: A GÊNESE DOS COMPORTAMENTOS SEGREGACIONISTAS NA PRIMEIRA INFÂNCIA
}

\author{
PREJUDICE AND CHILD EDUCATION: THE GENESIS OF SEGREGATIONIST \\ BEHAVIORS IN EARLY CHILDHOOD
}

\author{
Alessandra Maria Martins Gaidargi-Garutti \\ Doutora em Educação, Universidade Nove de Julho - UNINOVE \\ São Paulo, SP - Brasil \\ alessandra.gaidargi@gmail.com \\ José Eustáquio Romão \\ Doutor em Educação, Universidade Nove de Julho - UNINOVE \\ São Paulo, SP - Brasil \\ jerromao@gmail.com
}

\begin{abstract}
Resumo: O presente artigo apresenta apontamentos acerca da formação dos comportamentos de segregação na idade pré-escolar, suas raízes e motivações, a partir de pesquisa de caráter bibliográfico. São apresentados, neste estudo, dados sobre o comportamento das crianças em idade pré-escolar, que podem auxiliar o entendimento de seus parâmetros na formação comportamental e no estabelecimento de conceitos. Conclui-se que o preconceito não é inato, apontando a importância da mediação dos educadores em determinadas situações do cotidiano escolar, direcionando as relações para evitar que os agrupamentos naturais da humanidade, na busca por seus pares, se tornem instrumentos de ação preconceituosa entre os estudantes. A análise final aponta também para a necessidade da mediação respeitosa dos adultos nas relações entre as crianças no período da Educação Infantil, visto que estas ainda caminham para a autonomia, como é próprio da infância, e os cuidadores representam uma ponte com o mundo externo à escola.
\end{abstract}

Palavras-chave: Comportamento. Educação infantil. Infância. Preconceito.

Abstract: This paper presents notes about the formation of segregation behaviors at preschool age, its roots and motivations, based on bibliographic research. In this study, data on the behavior of children of preschool age are presented, which can help the understanding of their parameters in behavioral formation and in the establishment of concepts. It is concluded that prejudice is not innate, pointing out the importance of mediation by educators in certain situations of school routine, directing relationships to prevent the natural groups of humanity, in the search for their peers, from becoming instruments of prejudiced action among students. The final analysis also points to the need for respectful mediation by adults in the relationships between children in the Early Childhood Education period, as they still move towards autonomy, as is typical of childhood, and caregivers represent a bridge with the world outside the school.

Keywords: Behavior. Preschool. Childhood. Prejudice.

\section{Para citar - ABNT NBR 6023:2018}

GAIDARGI-GARUTTTI, Alessandra Maria Martins; ROMÃO, José Eustáquio. Preconceito e educação infantil: a gênese dos comportamentos segregacionistas na primeira infância. Cadernos de Pós-graduação, São Paulo, v. 19, n. 2, p. 33-47, jul./dez. 2020. Disponível em: https://doi.org/10.5585/cpg.v19n2.18366. 
Introdução

A natureza humana é a da busca por semelhantes. Entretanto, cada um sente-se mais atraído pela companhia de pessoas com diferentes características, desde a infância e, de acordo com Bloom (2014), faz parte também da natureza humana fazer estas distinções e até mesmo os bebês as fazem.

O período da Educação Infantil, em que as crianças encontram na escola um dos primeiros locais de sociabilização não familiar, por vezes, é o período em que os comportamentos segregacionistas se formam. Do cotidiano escolar surgem relacionamentos sociais que extrapolam os muros escolares e perduram ao longo da vida.

Ainda no tocante à natureza humana, Rogers (2009) defende que o natural, no ser humano, e nascer para viver e os condicionamentos sociais deturpados ensinam a destrutividade humana. Os comportamentos discriminatórios não seriam então inatos, mas aprendidos em algum momento da interação social. Considerando que as crianças, muitas vezes, apresentam comportamentos segregacionistas antes dos 5 anos de idade, pode-se considerar os ambientes familiar e da Educação Infantil como locais de desenvolvimento destes padrões.

Este artigo propõe-se a esclarecer a origem dos comportamentos discriminatórios entre as crianças e reunir dados científicos acerca dessa questão, a fim de embasar propostas mais assertivas para que os adultos, que mediam estas relações, possam orientá-las para um horizonte de gentileza e cooperação mútua.

\section{Empatia e criação}

Atualmente, o conceito de empatia tem sido um dos norteadores do trabalho pedagógico de inúmeras instituições de Educação Infantil e constantemente é associado ao conceito de compaixão. Mas, compaixão não é sinônimo de empatia: enquanto a primeira é sobre se preocupar com outras pessoas, a segunda é sobre se colocar efetivamente no lugar delas. Existe complementaridade entre estes conceitos, porém, se faz importante o trabalho com ambos para uma formação respeitosa. Enquanto a compaixão traz ideia de bondade com o outro, a empatia "leva a alegria pela alegria dos outros" (BLOOM, 2014, p. 53), num movimento de contágio do próximo. Mas, ainda assim, a empatia não é indispensável para despertar a compaixão.

$\mathrm{Na}$ teoria da comunicação não-violenta, Rosemberg (2006) defende que a natureza do ser humano é compassiva. Ter-se-ia em todos os seres humanos a mesma característica ao nascer: são bons com o próximo e o comportamento que se distancia disso seria consequência da criação e da forma com que se estabelecem as relações ao longo da vida. Entretanto há, nesta afirmação, uma delicada questão a se tratar: ainda que a violência não seja a forma natural de o ser humano lidar 
com o outro, a compaixão pelos desconhecidos talvez não seja despertada automaticamente. Segundo Bloom (2014), pessoas desconhecidas inspiram medo e aversão, em um primeiro momento.

A raiz dos comportamentos segregacionistas entre as crianças pequenas seria exatamente a falta de empatia e, não, de compaixão. Completamente apartado do conceito de maldade, ou de desejar o mal ao outro, os comportamentos preconceituosos entre crianças parecem se situar na esfera da incapacidade de se colocar no lugar do outro e de entendê-lo, não conseguindo, inclusive, entender a dor que pode ser infligida pelo comportamento discriminatório.

Diversos estudos já foram desenvolvidos com bebês e crianças pequenas para se compreender melhor a natureza de suas reações a pessoas desconhecidas. E, também, suas reações a pessoas desconhecidas que se encontram em um grupo diferente do seu, especialmente étnico e racial, sobre o qual já ouvem comentários e afirmações sociais por vezes preconceituosas. Os resultados (BLOOM, 2014) apontam para um senso moral existente desde o nascimento, em que até mesmo os bebês optam por privilegiar aqueles que são bons e compassivos. Porém, as crianças pequenas não teriam a capacidade abstrata de se colocar no lugar do outro para entender as diferenças e se aproximariam sempre daqueles que mais se parecem consigo mesmas.

\section{Racismo ou busca racial/étnica por pares?}

A questão do racismo na primeira infância é discutida e pesquisada por muitas correntes de pensadores na atualidade, porque urge a necessidade de novos posicionamentos sobre este assunto, a fim de que tenhamos meios mais eficientes de combatê-lo.

Para que se possa compreender o comportamento de segregação racial de algumas crianças, há que se entender qual sua origem. Estariam suas bases nas próprias diferenças étnicas da humanidade, originárias da simples preferência pelo que as crianças já conhecem?

Os bebês e crianças pequenas não mostram uma predileção apenas por pessoas que the são familiares de fato; eles o fazem com pessoas genericamente familiares, que têm os mesmos traços étnicos e até mesmo um sotaque mais parecido com o de seus pais e cuidadores. Há evidências (QUINN et al., 2002) de que bebês criados por mulheres passam mais tempo olhando para mulheres, por ser a identificação primária deles. Eles se sentem mais seguros perto de quaisquer mulheres do que de homens.

Bloom (2014) vai além, destacando pesquisas que documentam que bebês caucasianos preferem rostos caucasianos; bebês etíopes preferem rostos etíopes; bebês chineses preferem rostos chineses. Entretanto, isso não se dá apenas por identificação simples, visto que nestes estudos são considerados, inclusive, bebês que não se olham no espelho comumente para que estivessem refletindo sua imagem. A referência é a das pessoas que o cercam. Logo crianças criadas em ambientes 
etnicamente diversos se reconheceriam com mais segurança em outros indivíduos que se parecessem com aqueles que o cercam do que com aqueles que se parecessem com eles mesmos.

Sendo assim, poder-se-ia considerar que as questões do racismo na primeira infância devem ser atribuídas às diferenças étnicas que os rodeiam. E, posteriormente, o aprendizado sobre grupos específicos e as explicações religiosas e populares levariam as crianças ao comportamento discriminante, por medo, respeito ou identificação. Mas, essa seria uma resposta simplista e pouco efetiva. Ainda que estes aspectos devam ser levados em conta quando se avalia o grande quadro que esta questão representa é equivocado relativizar apenas como uma busca étnica por pares o comportamento discriminatório na primeira infância.

De acordo com Messick e Mackie (1989), codifica-se automaticamente a idade, o sexo e a raça de alguém que se acabou de conhecer. Estes seriam os dados primários sobre aquele indivíduo. $\mathrm{E}$ isso faz bastante sentido se se considera até mesmo as preferências das crianças: elas costumam preferir brincar com outras crianças de idades próximas e do mesmo sexo, por terem interesses parecidos. Mas, a raça é uma variável que nem sempre é levada em conta pelas crianças, nem pelos adultos.

Em um profundo estudo de Psicologia sobre a evolução natural, Kurzban, Tooby e Cosmides (2001) argumentam que a raça, nesta tríade das primeiras impressões que se tem, só é levada em conta quando está apoiada em coalizões. Coalizões estas que permitem a sobrevivência humana desde os antepassados humanos, mas que se modelam às necessidades de cada sociedade. Desta forma, "a raça torna-se importante porque, em algumas sociedades, as pessoas aprendem que a cor da pele e certas características físicas indicam a qual dos muitos grupos em conflito um indivíduo pertence" (BLOOM, 2014, p. 125).

De toda forma, entende-se que há uma tríade de primeiras impressões que atuam diretamente no sentimento que se tem em relação ao outro, no que diz respeito ao pertencimento ao grupo - e que seriam o gatilho para a seleção. A partir de Pratto, Sidanius e Levin (2006), esta tríade é formada por idade, sexo e um terceiro fator que é sempre social, mas que pode variar de acordo com os pontos mais acirrados de uma determinada sociedade ou território, podendo ser a raça, a religião, a etnia, o clã, ou outra característica que faça com que os indivíduos se sintam agrupados e coligados.

No Brasil a questão do racismo é um problema de grande magnitude, mas a questão religiosa também é importante em algumas regiões. Em alguns países, a religião, ou os traços étnicos são fatores de segregação intensos entre as crianças na educação infantil, muito mais representativos do que a diferença de raças. Teorias sobre o racismo e sobre a intolerância religiosa entre 
crianças levam em conta os fatores culturais e sociais que desencadeiam estas problemáticas; porém, estudos globais tendem a agrupar todas as características sociais que podem vir a causar segregação entre as crianças para compreender sua origem humana, para além das questões culturais que implicam.

\section{Hipótese de contato}

Uma das possibilidades elencadas nos estudos acerca dos comportamentos segregacionistas entre crianças é a de que essas relações se estabeleçam baseadas no desconhecimento do outro/diferente.

De acordo com Aboud (1988), desde a década de 1930, são realizados experimentos a fim de constatar em que grupos e de que forma a segregação acontece entre crianças, mais especialmente estudos norte-americanos voltados para compreender o racismo na primeira infância. Esses estudos refletem a preferência de crianças brancas por outras brancas e de negras por outras negras, como companheiros. Porém, um estudo em que se questionava qual criança era "mais boazinha", tanto crianças brancas quanto negras indicaram a criança branca, o que se alinha com o ideário de que o preconceito se forme entre as crianças ainda na educação infantil. A pesquisadora destaca que os estudos tinham uma característica que os tornava questionáveis: as crianças sempre precisam escolher entre uma e outra raça, sem outras variáveis, mas, ainda assim, são os marcos iniciais sobre o assunto.

Anos depois, com metodologia experimental aperfeiçoada, McGlothlin e Killen (2006) apresentaram pesquisa com crianças entre 6 e 9 anos sobre as questões raciais, sem, entretanto, forçá-las a escolher entre as raças. Ainda assim, as crianças brancas foram mais associadas a vítimas das situações e as negras como culpadas, em resultados bastante parecidos com os dos testes realizados décadas antes. Este estudo, porém, trouxe um novo olhar sobre a questão: as crianças que frequentavam escolas heterogêneas não se importavam com a raça e davam respostas aleatórias quanto aos culpados e não-culpados nas situações propostas. A heterogeneidade escolar, neste caso, vai muito além de uma organização escolar que proíba uma ou outra raça e tem mais conexão com as comunidades onde estas escolas estão localizadas. No Estados Unidos, assim como no Brasil, em muitas localidades, há um predomínio racial quase que absoluto, além de instituições escolares que, por fatores geográficos, financeiros e/ou culturais, são praticamente homogêneas nos quesitos raça e/ou etnia.

As escolas que incluem várias raças seriam, então, locais com circunstâncias adequadas para que comportamentos segregacionistas não se estabelecessem entre as crianças ao entrarem no Ensino Fundamental. Allport (1978) denomina esta característica "hipótese de contato". Em outras 
palavras, quando as crianças têm contato e interagem com crianças de outras raças, elas não desenvolvem preconceitos baseados no medo do desconhecido, mesmo que tenham sobre si a influência cultural da sociedade.

As crianças pequenas, de três anos, ainda na Educação Infantil, apresentam escolhas sem base em raça, independentemente do tipo de escola que frequentam. Kinzler, Corriveau e Harris (2011) demonstraram em seus estudos que, aos três anos, as crianças não fazem distinção por raça para escolher parceiros de jogos e colegas de atividades em sala. A partir dos cinco anos, quando as raças já são levadas em consideração, elas não são tão importantes quanto à linguagem para que as crianças escolham seus pares por atividades. Entretanto, nem a raça e nem a língua são suficientes para separar as crianças em coalizões, que seriam o fator decisivo para os comportamentos discriminatórios entre pré-escolares.

\section{Teoria da Coalizão}

Uma vez que o significado de coalizão é uma aliança em busca de um fim comum e que esta pode ter, inclusive, mais de um líder, podem-se encontrar coalizões em quase todas as organizações modernas, de torcidas de futebol a grupos políticos. Está-se sempre associando a pares, que são determinados por características específicas. A teoria da coalizão, que intenta explicar a origem da segregação entre crianças, estrutura-se sob o princípio de que é humano se associar a quem parece igual e isolar quem é diferente, por segurança, ou buscando melhores resultados evolutivos. Considerando este aspecto, "se a coalizão é o mais importante, não deveríamos esperar que as crianças se concentrassem na cor da pele ou em qualquer outra característica física" (BLOOM, 2014, p. 128).

Ainda de acordo com Bloom (ibid.), o mais lógico é que as crianças estabelecessem afinidade a partir de uma característica que é exclusivamente humana: a linguagem. Os processos de comunicação evoluem rapidamente durante a primeira infância, o que explicaria a seletividade das crianças na formação de grupos. Como a fala, exercida no dia-a-dia, alterar-se e adaptar-se mais rápido que outras características, como as físicas, a linguagem seria um potente indicador, talvez o mais potente indicador inclusive, da coalizão e do pertencimento ao grupo.

Em uma série de estudos sobre o comportamento na primeira infância acerca de variações linguísticas, Kinzler et al. (2002, 2007, 2009) e Shutts et al. (2009) trazem dados fundamentais para compreender este panorama: bebês, por volta de um ano de idade, preferem desconhecidos falantes do idioma dos pais, aceitando suas ofertas de brinquedos e alimentos, em detrimento das ofertas de adultos que falam outros idiomas, mesmo que nada seja dito no momento da oferta; crianças de 
dois anos preferem presentear crianças que falam seu idioma, independentemente de suas diferenças físicas e etárias; crianças de cinco anos preferem ter como amigos crianças que falam seu idioma, acima de quaisquer outras características. Estudo mais recente de Kinzler et al. (2011) refina este dado, demonstrando que crianças de 4 e 5 anos não somente preferem aqueles que falam seu idioma, mas aqueles que falam o mesmo idioma com o mesmo sotaque, os mesmos acentos e as mesmas construções gramaticais.

Considerando a teoria da coalizão para compreender melhor as origens do comportamento segregacionista na primeira infância, pode-se também considerar que a conscientização dos indivíduos, já na Educação Infantil, de que não estão em processo contínuo de conflito com o outro, é um caminho para que este comportamento não se estabeleça.

Neste sentido, a atividade mediadora dos educadores representa impacto direto no estabelecimento destes comportamentos. A atividade escolar tem caráter inexoravelmente mediado, em jogos e estudos. A mediação é então compreendida como um vínculo interposto, ligando o sujeito a um objeto, a um sistema social, ou a determinado conhecimento. A mediação é importante componente para a manifestação da humanidade no homem, que permite que ele ultrapasse as determinações essencialmente biológicas da espécie. A partir de Vygotsky (1993), o que permite aos sujeitos a inserção em sua realidade é a apropriação das significações históricas, possibilitada pela mediação de significados, dando, assim, significado à produção humana, ao lugar de cada um na teia social e às atividades como um todo.

Por outro lado, atividades não-mediadas tendem a reproduzir estruturas sem questionamento sobre a validade de seus argumentos; portanto, pode-se avaliar que a mediação adequada leva ao desenvolvimento humano, permitindo a reorganização dos contextos, a transformação e a melhoria de qualidade das relações interpessoais.

$\mathrm{Na}$ escola, a atividade pedagógica mediada facilita a tomada de consciência, o comportamento, a comunicação e as relações sociais. Vygotsky (1996) considera que os jogos e brincadeiras são a atividade principal que potencializa novas aprendizagens para as crianças e permite que adentrem a zona de desenvolvimento proximal. Mas, algumas significações elaboradas historicamente se estruturam sobre pressupostos opressivos e discriminatórios, cuja funcionalidade reside na exclusão e no estreitamento de possibilidades oferecidas aos seres humanos e, portanto, têm peso notável a mediação por parte dos educadores, para que manifestações preconceituosas não encontrem terreno fértil para propagação e interferência negativa no momento da atividade pedagógica.

Gramsci (1981) estabelece que os seres humanos se relacionam uns com os outros e com a sociedade, não por justaposição ou aglutinação, mas, organicamente, a partir da constituição de relações sociais. Retorna-se, então, à teoria da coalizão, sendo as relações e significados sociais 
criações humanas que não se caracterizam por serem eternas ou imutáveis, tendo diferentes sentidos e se modificando em contextos culturais específicos, A partir das ressignificações surgem novas coalizões. O estabelecimento de coalizões é uma predisposição da natureza, o que tende a perpetuar algumas inclinações sociais. Allport (1978) aponta que, talvez, seja impossível pensar sem o auxílio de categorias. Portanto, deve-se atentar para o período em que estas categorias começam a ser determinadas. Este apontamento implica profundamente na compreensão da manifestação de atitudes discriminatórias e preconceituosas no período pré-escolar, uma vez que elas têm sua gênese histórica em significados advindos da prática de relações sociais hierárquicas e opressivas, da rotulação pejorativa da diferença e da consequente exclusão dos que não se encaixam no padrão hegemônico dominante.

\section{Pré-conceito ou preconceito?}

A questão do preconceito na Educação Infantil precisa ser estudada com bastante cautela. Afinal, há que se distanciar pré-conceito (estágio anterior à criação dos conceitos pelas crianças), de preconceito (baseado em diferenciação discriminatória e pejorativa, causa do bullying). Há que se atentar para o que de fato é demonstração de preconceito, para não generalizar as atitudes propriamente infantis de tentativa de pertencimento aos grupos. De acordo com Bloom (2014), deixa-se contente o ser humano por pertencer a uma comunidade ou grupo específico, sejam crianças ou adultos. E “normalmente não é considerado errado se orgulhar e se preocupar com seu próprio grupo” (BLOOM, 2014, p. 149). Para tal distinção, é importante compreender o processo de formação dos conceitos e preconceitos e suas relações dialéticas. A formação de conceitos, de acordo com Vygotsky (2001), é um processo dinâmico, histórico e seriado, sendo todo conceito uma generalização configurada a partir de abstração de significações históricas. De acordo com este autor, os conceitos se caracterizam por "incorporarem à sua estrutura, como parte central de todo o processo, o emprego de signos como meio fundamental de orientação e domínio nos processos psíquicos" (VYGOTSKY, 2001, p. 161). Entretanto, para as crianças, essas significações estão ligadas a aspectos práticos e concretos, o que as coloca no campo de formação de conceito, por ainda não terem alcançado o nível de abstração exigida para a formação conceitual completa. Vigotsky acrescenta que:

[...] o desenvolvimento dos processos que finalmente culminam na formação de conceitos começa na fase mais precoce da infância, mas as funções intelectuais que, numa combinação específica, constituem a base psicológica do processo de formação de conceitos amadurecem, configuram-se e desenvolvem somente na puberdade (2001, p. 167). 
Sendo assim, para Vygotsky (2001), as expressões de aparentes conceitos emitidos por crianças na Educação Infantil teriam a relação de um embrião com um organismo maduro, ou seja, não podem ser consideradas pensamentos complexos completos.

É indispensável ressaltar-se esse caráter inicial da formação de conceitos das crianças para se compreender a distância entre todas as diferenciações promovidas por elas e aquelas que, de fato, demonstram comportamentos segregacionistas. O que as crianças utilizam são conceitos cotidiano-espontâneos, que diferem dos conceitos científicos. Todos expressam pseudo-conceitos eventualmente e, "estes conceitos cotidianos não são conceitos propriamente ditos do ponto de vista dialético" (VYGOTSKY, 2001, p. 218), são uma perspectiva generalista do mundo e as crianças utilizam muito este padrão por não terem ainda conceitos formados acerca das grandes questões humanas.

\begin{abstract}
Ao nascermos necessitamos de nos apropriar de uma série de conceitos para efetivamente intervirmos na sociedade. Muitos desses conceitos são apropriados a partir das relações direto-assistemáticas (embora sejam sempre mediadas) pelas quais entramos em contato com os objetos ao nosso redor: os conceitos de mãe, pai, irmão, árvore, animal situamse nesse estádio. Outros apenas são apropriados mediante uma intervenção sistematizada (comumente na infância realizada por professores), em que geralmente tomamos conhecimento inicialmente do conceito para depois aplicá-lo ou refutá-lo na prática: aqui podem ser encontrados os conceitos da lei de Arquimedes, da teoria da relatividade, de preconceito, assim como dos conceitos também referendados anteriormente como os de cidade, bairro, rua, rio, animal, irmão, pai e mãe, cujo direcionamento segue da definição para o objeto, do abstrato para o concreto. É dessa maneira que tentamos compreender e dar sentido à nossa existência (PICCOLO, 2008, p. 56).
\end{abstract}

Os conceitos começam a se formar na primeira infância, tanto cotidianos quanto científicos, mas "o nascimento dos conceitos científicos começa não com um encontro imediato com coisas, mas com um relacionamento mediato para um objeto. Com o conceito espontâneo a criança se move das coisas para o conceito" (id., ibid., p. 219). Em outras palavras, o conceito científico, complexo, é formado a partir das relações da criança com o mundo e a partir dos pré-conceitos. É necessário um longo processo histórico-cultural para que a criança tome a consciência necessária para transformar um pseudo conceito em um conceito. E, de acordo com Vygotsky (ibid.), é exatamente neste momento, que o pensar transcende o limite do pré-conceito para o campo dos verdadeiros conceitos.

Aprendizagem e desenvolvimento de conceitos são processos que se relacionam de forma dialética e acontecem, concomitantemente, na primeira infância. A partir dessa lógica, fica claro que a maneira pela qual se trata do processo de formação humana interfere-se na criação de conceitos a partir dos pré-conceitos.

Ainda que os dicionários definam preconceito como opinião formada antecipadamente ou ideia pré-concebida, esta definição está mais próxima do que se chama, aqui, de pré-conceito, ou 
conceito em fase de experimentação. O preconceito tem características discriminatórias e alienantes, como a manutenção dos estereótipos pejorativos contra determinada pessoa ou grupo social. O preconceito carrega em si "uma estrutura simbólica e material que qualifica pejorativamente tudo o que difere de determinado modelo social tido como hegemônico" (PICCOLO, 2008, p. 78) diante de estereótipos incorporados em todo tipo de processo de comunicação cotidiano.

Heller (1970) define pré-conceito como pré-conhecimento sobre determinado fato, condição essencial à construção de qualquer saber complexo. Uma ideia superficial à qual cabe uma evolução para a formação de um conceito. Já os preconceitos têm caráter sectário, em que observase uma deturpação conceitual. Os preconceitos não são de teor biológico ou hereditário. De origem histórica e social é produto humano para justificar relações sociais baseadas em diferenças econômicas, culturais e religiosas, entre outras. As diferenças passam a ser consideradas desigualdades, cristalizando estereótipos e consolidando modelos hegemônicos. O preconceito é tão antigo quanto as relações de poder nas sociedades e é de origem social e cultural.

A partir de Gramsci, pode-se entender que um dos fatores que possibilita a manutenção e disseminação dos preconceitos é a falta de conhecimento dos homens sobre o desenvolvimento histórico de sua realidade social, em que estão as raízes de todos os preconceitos. A necessidade de pertencimento sem o devido conhecimento de sua própria história leva o homem a comportamentos segregacionistas e preconceituosos. "Pela própria concepção de mundo, pertencemos sempre a um determinado grupo, precisamente o de todos os elementos sociais que partilham de um mesmo modo de pensar e agir" (GRAMSCI, 1981, p. 12) e, a partir disso, nos tornamos conformistas em algum sentido, porque somos homens coletivos.

Os processos de apropriação de atitudes preconceituosas são muitos e alguns são particularmente acessíveis às crianças pequenas, como a imitação de padrões exercidos por adultos que admiram, ou a reprodução de ideias que ecoam socialmente sem respaldo científico. Mas, esse processo não evolui para a formação de um conceito como no pré-conceito; ele apenas se reproduz por não ter um fundamento real. De acordo com Heller (1991), a mediação das relações entre as crianças na Educação Infantil tem caráter fundamental para que esses preconceitos não se disseminem, para que os pré-conceitos sigam o curso "normal" de formação de conceitos e não se cristalizem em preconceitos.

Para Allport (1974), preconceito é a ação hostil contra determinado indivíduo ou grupo, tentando impor à sociedade valores que devem ser aceitos ou não, em determinado contexto. Seus alvos são grupos desvalorizados, desiguais ou minoritários. E entre as crianças na idade pré-escolar já é possível notar a formação de grupos por identificação física e étnica. A mediação das relações 
entre as crianças pelos educadores pode interferir na formação dos preconceitos a partir do momento que esclarecem o equívoco da construção de conceitos com base na aparência material ou simbólica e conduz as crianças à construção de conceitos reais com significações estáveis. A contestação dos preconceitos no período pré-escolar deve vir acompanhada da exemplificação da teoria, visto que, nesta faixa etária, as crianças ainda não têm a capacidade de abstração necessária para a sistematização de conceitos abstratos e, sem o aporte da mediação, elas não conseguem ascender ao sistema de relações que é característico do pensamento conceitual.

No que tange especificamente ao preconceito em sua incidência entre as crianças pequenas, pode-se identificar múltiplas gradações. Piccolo, em pesquisa sobre a manifestação social do preconceito na atividade principal de jogos na Educação Infantil, divide o ciclo do preconceito em 3 fases: rotulação pejorativa da diferença; discriminação da diferença e manutenção das atitudes discriminatórias mesmo após a tomada de consciência dos fatos, ou a cristalização do preconceito. Este autor acrescenta:

Na pré-escola, com raras exceções, as manifestações preconceituosas se concretizam na consubstanciação das duas primeiras fases, não se observando a cristalização dos preconceitos, o que dá importância crucial às mediações pedagógicas na arquitetura de relações sociais mais fraternas e solidárias. Por meio dessas relações as crianças passam a entender a diferença não como desigualdade, mas como a expressão histórica da humanidade contidas nas mais diversas culturas, sociedades e seres humanos (2008, p. 5).

Entretanto, é importante ressaltar, mais uma vez, que nem toda associação em grupos deve ser encarada como representação de preconceito entre as crianças pequenas. Um exemplo são as coalizões por habilidades esportivas. As crianças em idade pré-escolar ainda não dominam o pensamento abstrato de que os colegas menos hábeis são aqueles que mais precisam se dedicar ao desenvolvimento corpóreo-culturais; eles apenas escolhem os mais hábeis para seu time a fim de vencer a competição. Isto não se constitui em um preconceito com uma criança portadora de necessidades especiais, por exemplo, porque é apenas a expressão humana e natural da busca por pares para fortalecimento conjunto. Mas, é fundamental que haja, nesses momentos, a mediação do educador para que essa atitude de exclusão da diferença não complete o ciclo e se concretize em um preconceito contra o diferente.

Além da interrupção do ciclo de cristalização do preconceito, a mediação positiva dos educadores possibilita a compreensão das diversas relações com o diferente, não deixando espaço para a adoção de comportamentos preconceituosos. E isto se dá, todo o tempo, nas práticas educativas e lúdicas. 


\section{A questão da linguagem}

A linguagem também pode se tornar um instrumento para a formação de coalizões na primeira infância. Sendo a busca por pares o mais importante, "não deveríamos esperar que as crianças se concentrassem na cor da pele ou em qualquer outra característica (...) elas deveriam prestar atenção em algo que fosse exclusivamente humano - a linguagem” (BLOOM, 2014, p. 128).

Rosenberg (2006) defende que a natureza do ser humano é compassiva e que a linguagem e o uso das palavras exercem um papel crucial na manutenção desse estado natural de compaixão, mesmo nas situações mais dolorosas e difíceis. Com base nesta referência, poder-se-ia dizer que a linguagem mais ou menos afetuosa seria o elemento divisor de grupos, mas não é exatamente isso que as pesquisas mostram. Ainda que o formato da linguagem tenha peso para as crianças, o mais importante para elas é a proximidade de sons e pronúncias; é a partir daí que se estabelecem coalizões.

Experimentos de Kinzler et al. (2007, 2009) mostram que as crianças pequenas preferem sempre falantes do mesmo idioma e sem sotaque, o que demonstra também a vinculação cultural aí contida. Estes estudos demonstraram que, inclusive a oferta de alimentos, ligada ao instinto básico da fome, é melhor aceita pelas crianças se vinda de um falante com a mesma característica linguística que o sua. "Os bebês conseguem reconhecer a língua à qual foram expostos, e preferemna a outras línguas, mesmo que falada por um desconhecido" (BLOOM, 2014, p. 129). Essas inclinações fazem bastante sentido, visto que é mais fácil estabelecer relações com pessoas que falam a mesma língua, que se compreendem melhor. Entretanto, nem a raça/etnia, nem a língua, podem ser consideradas essenciais para a formação de coalizões. O estabelecimento da fidelidade em um grupo é baseado em diversas variáveis que perpassam as questões de linguagem, mas também as questões étnico-raciais, religiosas e de ordem política. Sendo assim, não há um consenso sobre o fato gerador do preconceito entre crianças ou adultos, mas há um entendimento coletivo de que a formação destes comportamentos se inicia na infância e têm como base os fatores sociais aos quais as crianças são expostas.

\section{Considerações finais}

A partir dos apontamentos aqui feitos, pode-se concluir que o preconceito não é inato; ele nasce das coalizões estabelecidas entre grupos sociais por diversos motivos e que, por sua vez, têm base na característica humana da busca por pares.

Allport (1978) defende que o preconceito é construído; não é hereditário e nem faz parte da natureza humana nascer preconceituoso - ainda que faça parte da natureza humana agrupar-se de acordo com algumas características comuns. O preconceito se instala no desenvolvimento das 
relações sociais e na necessidade de defesa social daqueles que são diferentes e, com isso, de alguma forma o ameaçam.

Por ser um comportamento aprendido socialmente, o preconceito tende a ser reproduzido tanto pelos que cercam a atitude, quanto pelo próprio autor, que, possivelmente, passa a ter comportamentos preconceituosos perante outros grupos. Por vezes, há uma relativa independência entre quem mantém o comportamento preconceituoso e o próprio objeto. Portanto, uma vez que os estímulos ao comportamento preconceituoso atingem as crianças desde a mais tenra idade, é primordial que as mediações dos adultos esclareçam o equívoco deste comportamento desde a idade pré-escolar, inclusive no âmbito da escola.

Atitudes segregacionistas e preconceituosas podem levar as crianças a uma distorção da realidade, o que compromete, inclusive, seu desenvolvimento. A formação inicial de conceitos está acontecendo no período da primeira infância e a incidência de rotulações pejorativas sem fundamentação pode levar a desvios no processo de formação conceitual, uma vez que as crianças se encontram na zona de desenvolvimento proximal. Em outras palavras, a aquisição de (pré)conceitos determinados que não seguem um padrão lógico pode levar ao entendimento de que os conceitos, em geral, também não precisam seguir este caminho.

Isso se sustenta porque não é possível afirmar que o preconceito derive das características de seus objetos, ainda que estas não lhe sejam indiferentes. Logo, o que desperta o preconceito é algo percebido nele e a atribuição dessa característica é dada por aquele que comete o ato preconceituoso. Desta forma, uma vez aprendido o comportamento segregacionista, ele tende a se repetir ainda que com objetos e grupos diferentes, porque passa a ser uma forma de defesa da criança com tudo que se mostra diferente e a ameaça de alguma forma.

A compreensão da dinâmica das relações entre as crianças em fase pré-escolar, sejam de caráter religioso, sejam étnico-raciais, ou de outro caráter, e a proposta de mediação educativa nestas relações são recursos de combate às desigualdades que se desenham na sociedade contemporânea, voltados para a construção de relações mais respeitosas entre os cidadãos. Só é possível falarse em uma educação igualitária desde os primeiros anos escolares se se considerar a necessidade de que a igualdade seja um conceito trabalhado de forma dirigida entre as próprias crianças.

Considerando a falta de autonomia característica da primeira infância, é responsabilidade dos adultos pela Educação Infantil e pela mediação das relações, apontar caminhos para o desenvolvimento ético e moral respeitoso dessas crianças, para que não se tornem vítimas de preconceitos difundidos inadvertidamente na sociedade todos os dias. 


\section{Referências}

ABOUD, Frances. Children and prejudice. Oxford: Basil Blackwell Inc, 1998.

ALLPORT, Gordon. Personalidade: padrões e desenvolvimento. São Paulo: EPU, 1974.

ALLPORT, Gordon. The Nature of Prejudice: 25th Anniversary Edition. Nova Iorque: Basic Books, 1978.

GRAMSCI, Antonio. Concepção dialética da história. Rio de Janeiro: Civilização Brasileira, 1981.

HELLER, Agnes. O cotidiano e a história. São Paulo: Paz e Terra, 1970.

HELLER, Agnes. Sociologia de la vida cotidiana. Barcelona: Península, 1991.

KINZLER, Katherine; DUPOUX, Emmanuel; SPELKE, Elizabeth. The native language of social cognition. Proceedings of the National Academy of Sciences, n. 104, p.12577-12580, 2007.

KINZLER, Katherine; SHUTTS, Kristin, JESUS, Jasmine; SPELKE, Elizabeth. Accent trumps race in guiding children's social preferences. Social Cognitio, n²7, p.623-634, 2009.

KINZLER, Katherine; CORRIVEAU, Kathleen; HARRIS, Paul. Children's selective trust in native-accented speakers. Developmental science, n¹4, p.106-111, 2011.

KURZBAN, Robert; TOOBY, John; COSMIDES, Leda. Can race be erased? Coalitional computation and social categorization. Proceedings of the National Academy of Sciences, n. 98, p.15387-15392, 2001.

McGLOTHLIN, Heidi; \& KILLEN, Melanie. Intergroup attitudes of European America children attending ethnically homogeneous schools. Child development, n. 77, p.1375-1386, 2006.

MESSICK, David; MACKIE, Daiane. Intergroup relations. Annual review of psychology, n 40, p.4581, 1989.

PICCOLO, Gustavo. Educação infantil: análise da manifestação social do preconceito na atividade principal de jogos. Säo Carlos: UFSCar, 2008.

QUINN, Paul et al. Representation of the gender of human faces by infants. Perception, n. 31, p. $1109-1121,2002$.

ROGERS, Carl. Tornar-se Pessoa. São Paulo: Martins Fontes, 2009.

ROSEMBERG, Marshall. Comunicação Não-Violenta. São Paulo: Ágora, 2006.

SHUTTS, Kristin; KINZLER, Katherine; Mckee Caitlin; SPELKE, Elizabeth. Social information guides infants selection of foods. Journal of cognition and development, n. 10, p.1-17, 2009.

PRATTO, Felicia; SIDANIUS, Jim; LEVIN, Shana. Social dominance theory and the dynamics of intergroup relations: Taking stock and looking forward. European review of social psychology, n. 17, p. 271-320, 2006. 
VYGOTSKY, Lev. Obras escogidas. Volume 2. Madrid: Aprendizaje Visor, 1993.

VYGOTSKY, Lev. Obras escogidas. Volume 4. Madrid: Aprendizaje Visor, 1996.

VYGOTSKY, Lev. A construção do pensamento e da linguagem. São Paulo: Martins Fontes, 2001. 